\title{
Denaturation processes of collagen from cow bones as a function of temperature
}

\author{
Melania Lucila Lambri ${ }^{1,2}$, Patricia Beatriz Bozzano ${ }^{3}$, Enrique David Victor Giordano ${ }^{2,4}$, \\ Federico Guillermo Bonifacich ${ }^{2}$, Damián Gargicevich ${ }^{2}$, Griselda Irene Zelada ${ }^{2}$, \\ Osvaldo Agustín Lambri ${ }^{2}$
}

\author{
${ }^{1}$ Facultad de Humanidades y Artes, Universidad Nacional de Rosario, Entre Rios 758, CP: 2000 Rosario, Santa Fé, Ar- \\ gentina. \\ e-mail: melania.lambri@gmail.com \\ ${ }^{2}$ CONICET-UNR, Laboratorio de Materiales, Escuela de Ingeniería Eléctrica, Centro de Tecnología e Investigación Eléc- \\ trica, Facultad de Ciencias Exactas, Ingeniería y Agrimensura, Av. Pellegrini 250, CP: 2000, Rosario, Santa Fé, Argenti- \\ na. \\ e-mail: david_giordano@outlook.com,bonifaci@fceia.unr.edu.ar; gargi@fceia.unr.edu.ar; \\ gizelada@fceia.unr.edu.ar; olambri@fceia.unr.edu.ar \\ ${ }^{3}$ Laboratorio de Microscopía Electrónica, Unidad de Actividad Materiales, Centro Atómico Constituyentes, Comisión \\ Nacional de Energía Atómica e Instituto Sábato - Universidad Nacional de San Martín, \\ Avda. Gral. Paz 1499, CP: 1650, San Martín, Buenos Aires, Argentina. \\ e-mail: pbozzano@cnea.gov.ar \\ ${ }^{4}$ CONICET - IPROBYQ, Área de Tecnología Química, Facultad de Ciencias Bioquímicas y Farmacéuticas, Suipacha \\ 531, CP: 2000, Rosario, Santa Fé, Argentina.
}

\begin{abstract}
The thermal stability of collagen is of great interest for the scientific communities both of medicine and archaeology. In medicine, the interest is focused to the reconstruction and repair of bone and cartilage, given the frequency and importance of pathological situations. In contrast, in archaeology the interest is focused to infer from buried and/or burned bones the behavior and habits of people who once inhabited archaeological sites. In bones from cow ribs, the biodegradation of collagen by denaturation of albumin and haemoglobin proteins, the loss of water and the loss of crystallization water during warming up to around $450 \mathrm{~K}$, have been studied. In addition, from an easy-to-handle mathematical viscoelastic procedure, it was determined that the conformational changes from the collagenic triple helix towards the random coil are made through the viscous movement of fibrils, invoking an activation energy of $(127 \pm 8) \mathrm{kJ} / \mathrm{mol}$. In the present work, the thermal stability of type I collagen from cow bones, either femur and rib, was studied in the temperature range from $250 \mathrm{~K}$ up to $670 \mathrm{~K}$ by means of dynamic mechanical analysis, scanning electron microscopy and infrared absorption spectroscopy. In fact, this temperature range is wider than the previous explored ones. Several stages of denaturation were found in the temperature range from $320 \mathrm{~K}$ up to $670 \mathrm{~K}$, including also the transition from the triple helix $(\mathrm{TH})$ towards the random coil (RC) of the collagen fibrils. The temperature for the $\mathrm{TH} \rightarrow \mathrm{RC}$ transition was approximately the same for all the kinds of bones, but the intensity of the relaxation processes depended upon the kind of bone. The differences between the denaturation processes in the femur and rib are highlighted and the physical-chemical mechanisms controlling the denaturation processes are discussed. In fact, different behaviours of the mesostructure were found between the cortical parts of bones from ribs and femurs. In addition, the cancellous parts from ribs bone exhibits the survival of organic compounds even at temperatures as higher as $673 \mathrm{~K}$. The results from the present work are crucial both for the tissue engineering, focused to bone replacement and pathologic treatments, and for the archaeology, for the study of identification of buried and/or burned bones in archaeological sites.
\end{abstract}

Keywords: Archaeometry, bone repair, thermal denaturation, tissue engineering, cow bones.

\section{INTRODUCTION}

Bone is defined as a natural composite material composed by $20-25 \mathrm{wt} \%$ of organic constituents, around 70 $\mathrm{wt} \%$ of inorganic constituents, and around $5 \mathrm{wt} \%$ of water. About $98 \%$ of type I collagen and noncollagenous protein form the organic constituent [1]. 
In all connective tissues, collagen has mechanical functions, providing elasticity and structure for the component tissues. Several studies indicate that collagen plays a substantial role in its toughness, while the mineral content is mainly involved in determining bone stiffness. Alterations of collagen properties can therefore affect the mechanical properties of bone and increase fracture susceptibility. Numerous studies suggest that part of the large variation in bone strength may be related to differences in the quality of the collagenous matrix, including the nature and extent of its posttranslational modifications [2-7].

The collagen molecule consists of triple helical tropocollagen molecules at nanometric scale. Staggered arrays of collagen molecules form fibrils, which arrange to form the collagen fibers [8] where the carbonated apatite crystals ('dahllite') are embedded $[1,9,10]$.

In previous works the biodegradation of collagen by denaturation of albumin and haemoglobin proteins, the loss of water and the loss of crystallization water during warming up to around $450 \mathrm{~K}$, in cow ribs bones, has been studied [11,12]. In fact, by coupling dynamic mechanical analysis (DMA), differential scanning calorimetry (DSC), thermogravimetry (TGA) and scanning electron microscopy (SEM), the physical-chemical mechanisms that control the wide damping maximum in bones samples, between around $280 \mathrm{~K}$ and $420 \mathrm{~K}$, were determined. This maximum is the result of the overlapping of different processes taking place at different temperatures in the cancellous and cortical parts. A damping peak at around $320 \mathrm{~K}$ develops both in cancellous and cortical bone. It is controlled by the overlap of the following processes: (i) the denaturation of albumin and haemoglobin proteins and also the melting of fats, (ii) the loss of water during heating at temperatures over room temperature. A damping peak at $350 \mathrm{~K}$ appears in cancellous bone only and is controlled by the shrinkages of the mesostructure of bone owing to the loss of water. The collagen/protein denaturation and the loss of crystallisation water, in cortical bones, give rise to another relaxation process from around $390 \mathrm{~K}$ up to $410 \mathrm{~K}[11,12]$. More recently, through studies performed on cow rib bones, two denaturation processes of type I collagen in the temperature range between $450 \mathrm{~K}$ and $670 \mathrm{~K}$ were determined. The conformational changes of the collagen molecules from a triple helix $(\mathrm{TH})$ structure to a random coil $(\mathrm{RC})$ were found at around $510 \mathrm{~K}$. In addition, from an easy-to-handle mathematical viscoelastic procedure, it was determined that the $\mathrm{TH} \rightarrow \mathrm{RC}$ transition is made through the viscous movement of fibrils, invoking an activation energy of $(127 \pm 8) \mathrm{kJ} / \mathrm{mol}$. A subsequent stage of massive bulk deterioration of the collagen was found at around $600 \mathrm{~K}$ which leads to the loss of the mechanical integrity of the bulk collagen [10]. Indeed, bone characterization under thermal conditions is an excellent method of measuring the degree of both crosslinking and crystallinity at which collagen denatures from a triple helix to a random coil structure [1].

In the present work, the thermal stability of type I collagen from cow bones, either femurs and ribs was studied in the temperature range from $250 \mathrm{~K}$ up to $670 \mathrm{~K}$ by means of DMA, SEM and infrared absorption spectroscopy (IR). Several stages of denaturation were found in the temperature range from $320 \mathrm{~K}$ up to $670 \mathrm{~K}$ which depend upon the bone kind. These findings are very significant because they confer an important tool for the study of the physical-chemical processes related to the denaturation of collagen which are of high interest both in the field of medicine [13,14] and archeology [15-17].

\section{MATERIALS AND METHODS}

\subsection{Samples}

Cortical and cancellous bones from ribs and cortical bones from femur of fresh cow meat were supplied by three different local providers. Samples from ribs bones were taken by cutting with a jeweller saw in perpendicular direction to its longest dimension, Figure 1.a., see for more details Refs. [10-12]. In contrast, for femur samples, firstly, a cylinder of around $150 \mathrm{~mm}$ length was cut from the entire femur by means of a saw. Subsequently, small parallelepiped samples, oriented along the axis of the bone were cut with a jeweller saw, Figure 1.b. Three samples from the bone of each provider were taken. For MS and IR, the samples were in parallelepiped shape of around $3 \mathrm{~mm}$ x $4 \mathrm{~mm}$ x $40 \mathrm{~mm}$, the final size being reached by means of mechanical polishing.

\subsection{Measurements}

DMA studies, which involve the simultaneous measurement of damping $(\tan (\phi))$ and natural oscillating frequency (f) as a function of temperature (T) [18], were performed at frequencies close to $25 \mathrm{~Hz}$; within the temperature range from $250 \mathrm{~K}$ up to $670 \mathrm{~K}$. In fact, the dynamical response of a linear viscoelastic material is usually described in terms of the complex modulus $\mathrm{G}^{*}$ (or complex compliance $\mathrm{J}^{*}$ ) as a function of the circular frequency $\omega(\omega=2 \cdot \pi \cdot f)$ and T. The complex modulus is generally presented in terms of its real and 
imaginary parts, that is, $G^{*}=G^{\prime}+i G^{\prime}$, where $G^{\prime}$ is the storage modulus, $G^{\prime \prime}$ is the loss modulus and i is the imaginary unit. Consequently, $\tan (\phi)$ is defined as the quotient between the imaginary and real part of the complex modulus [18]. In addition, a proportionality between $G^{\prime}$ and the squared natural oscillating frequency can be established. The proportionality constant involves the moment of inertia of the oscillating system and the dimensions of the sample [19].

a)

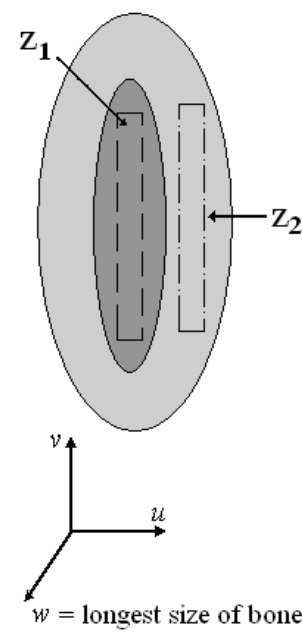

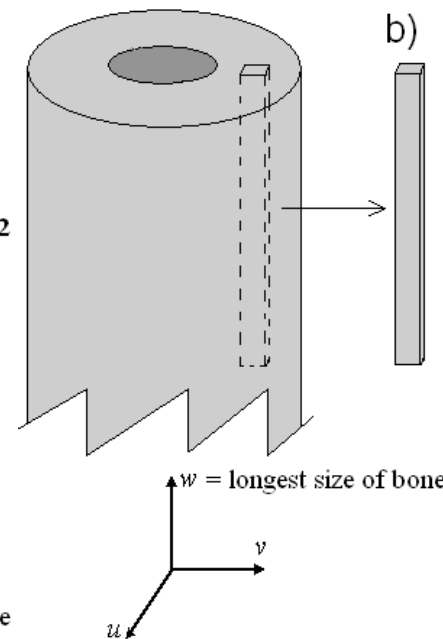

Figure 1: (a) Schematic representation of a section of a rib bone obtained by cutting with the jeweller saw. $Z_{1}$ : Zone delimited by dashed lines from where the cancellous sample was obtained. $\mathrm{Z}_{2}$ : Zones delimited by alt-dashed lines from where the cortical samples were obtained. (b) Schematic representation of a section of a femur bone showing from where the sample was taken.

DMA tests were carried out in torsion, under pure argon atmosphere at standard pressure. The heating and cooling rates were of $1 \mathrm{~K} / \mathrm{min}$. The maximum shear strain on the sample was $2 \times 10^{-4}$. The error for damping and $\mathrm{f}^{2}$ (which is proportional to the dynamic shear modulus) was less than $2 \%$.

SEM studies were performed in a FEI Quanta 200 scanning electron microscope operated at $15 \mathrm{kV}$, under vacuum.

IR studies were carried out in a Shimadzu Prestige 21, FTIR spectrometer, with an attenuated total reflectance (ATR) accessory. For each studied sample 40 scans per spectrum, in the wavenumber range of $4000-400 \mathrm{~cm}^{-1}$ with a resolution of $4 \mathrm{~cm}^{-1}$, were used.

\section{RESULTS AND DISCUSSION}

Figure 2.a shows the damping spectra measured during warming in cortical and cancellous bones parts from cow ribs bones and cortical bones from cow femur. Several relaxation peaks are recorded, P1 to P6, whose approximate peak temperature is indicated by means of vertical arrows in the Figure. The corresponding modulus curves are shown in Figure 2.b, where the approximate peak temperature is also indicated by means of vertical arrows in order to show the effects of the relaxation processes on the modulus. The ratio between the elastic modulus as a function of temperature, $\mathrm{G}^{\prime}(\mathrm{T})$, and the values of the modulus at room temperature (RT), G'(RT); G'(T)/G'(RT), has been used for easing the comparison of the modulus among the different kinds of samples since the large difference among absolute moduli values for the different tested samples (around 50\%). It should be pointed out, the good agreement between the peak temperature of damping relaxation processes and the changes in slope in the moduli curves.

The measured curves of damping and modulus for samples taken from different bones exhibited a discrepancy up to around 50\%, in agreement with previous works [10-12]. Nevertheless, the general trends of the curves for damping and modulus are completely similar and reproducible.

In order to improve a clearer observation of the damping and modulus behaviours in the zone of temperatures between room temperature (RT) and $450 \mathrm{~K}$, Figures 3.a and 3.b are shown; respectively. As it can be seen from Figures 2 and 3, the cancellous bone from cow ribs exhibits the damping peaks P1 and P2 at around $320 \mathrm{~K}$ and $350 \mathrm{~K}$, respectively. P1 peak is controlled by the overlap of the following processes: (i) the denaturation of albumin and haemoglobin proteins and also the melting of fats, (ii) the loss of water during heating at temperatures over room temperature. In addition, P2 peak is controlled by the shrinkage of the 
mesostructure of bone owing to the loss of water [11,12]. The development of P1 and P2 peaks are related to a nearly constant behaviour of the modulus up to around $320 \mathrm{~K}$, followed by an increase due to the shrinkage of the mesostructure promoted by the loss of water [9-12].

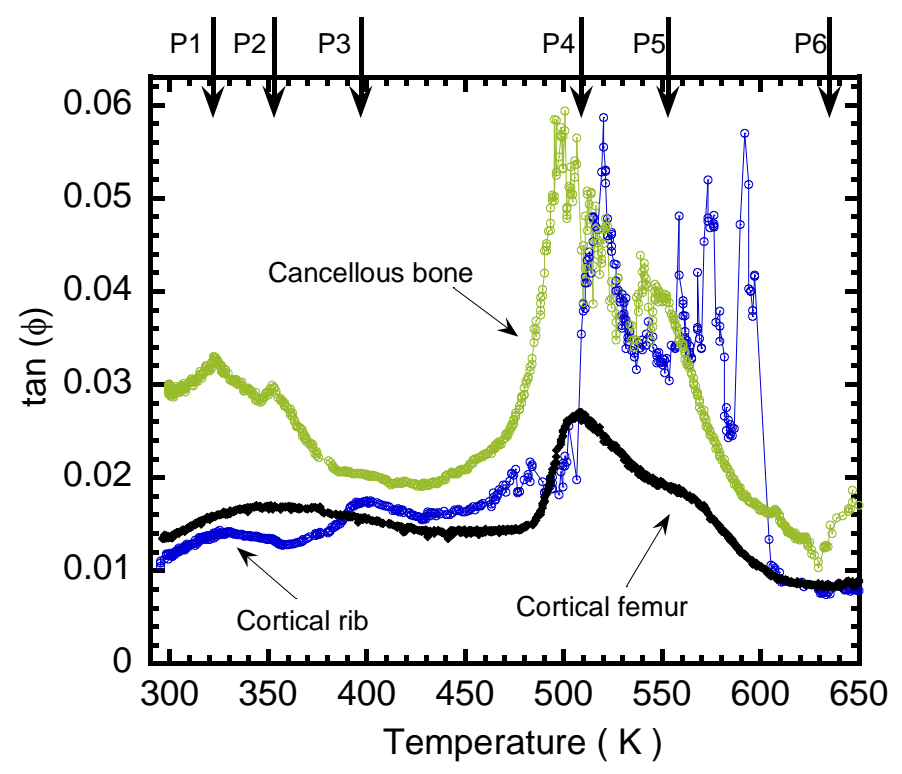

Figure 2a: Damping $(\tan (\phi))$ as a function of temperature for cortical and cancellous bones parts from cow ribs and cortical femur samples.

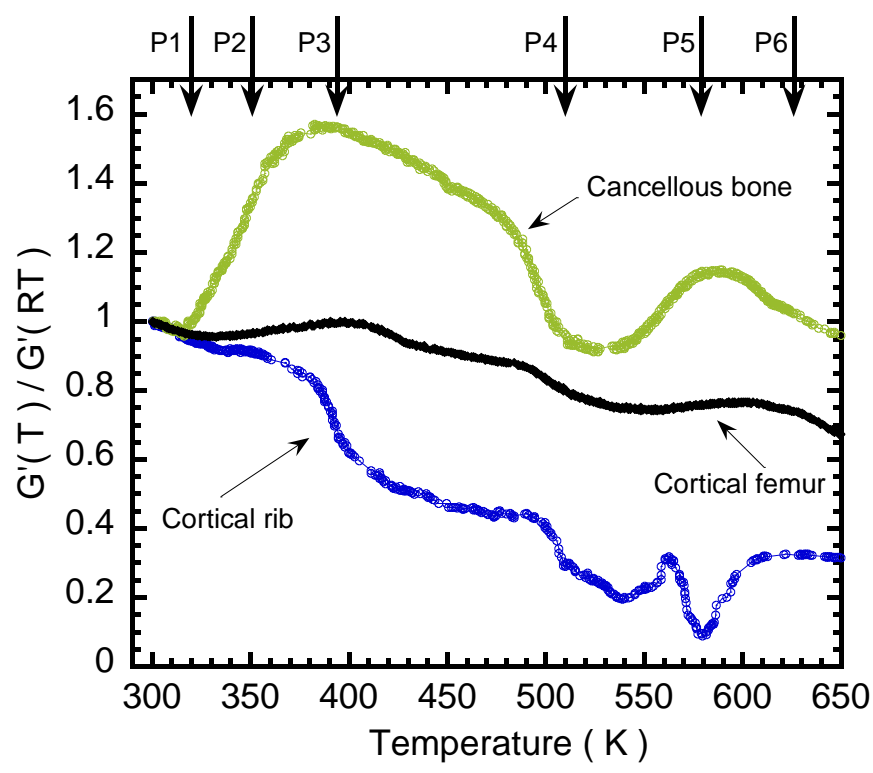

Figure 2b: Elastic modulus as a function of temperature for cortical and cancellous bones parts from cow ribs and cortical femur samples.

The cortical part of the cow ribs bone, exhibits also the P1 peak, but the P2 peak is not clearly resolved, even if it could be assumed to appear very small overlapped to P1 peak, which is in agreement with previous reported works [12]. In fact, in the cortical part of ribs bones P2 peak was not reported [12]. In addition, the cortical part of the cow ribs bone gives rise to the appearance of a clear relaxation peak, P3, at around $390 \mathrm{~K}-410 \mathrm{~K}$; which is accompanied by a clear relaxation in the modulus curve. P3 peak is absent in the cancellous part of the cow ribs bone, in agreement with previous works [12]. The driving force controlling P3 was related to the collagen/protein denaturation and the loss of crystallisation water [12].

In contrast, the cortical bone taken from cow femur, exhibits a wide damping peak, which involve in 
its temperature range to $\mathrm{P} 1, \mathrm{P} 2$ and $\mathrm{P} 3$ peaks. Besides, the corresponding modulus curve shows the changes related to the appearance of these peaks. In fact, the modulus shows a first decrease up to $320 \mathrm{~K}$ related to P1 peak, followed by an increase from around $320 \mathrm{~K}$ up to $390 \mathrm{~K}$ related to P2 peak and finally the step down from $390 \mathrm{~K}$ onwards related to $\mathrm{P} 3$ peak.

Therefore, the first difference between ribs and femur bones arise. Indeed, the cortical femur exhibits the appearance of P2 peak, which should be related to the shrinkage of the mesostructure of bone owing to the loss of water. Moreover, this behaviour is in agreement with the increase exhibited by the modulus curve (see Figure 3.b).

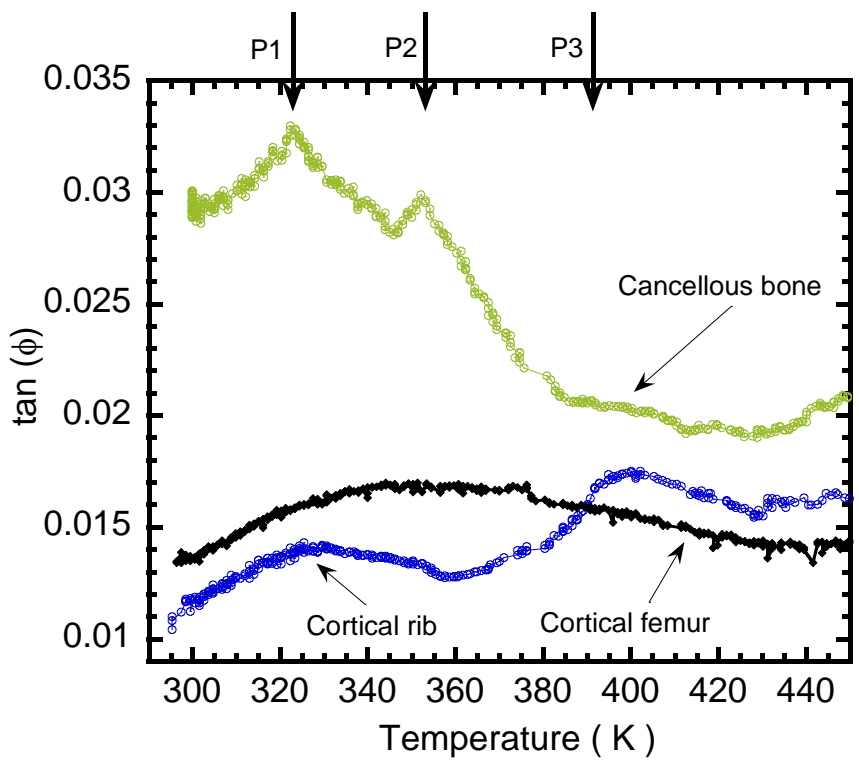

Figure 3a: Zoom of the temperature zone between RT and $450 \mathrm{~K}$ from Figure 2.a. Damping $(\tan (\phi))$ as a function of temperature for cortical and cancellous bones parts from cow ribs and cortical femur sample.

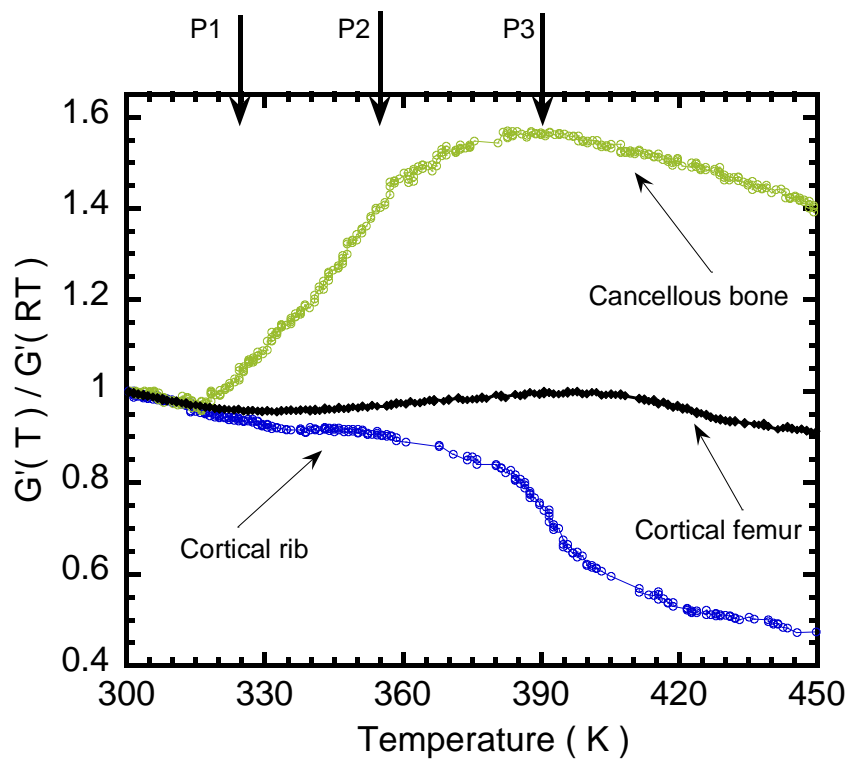

Figure 3b: Zoom of the temperature zone between RT and $450 \mathrm{~K}$ from Figure 2.b. Elastic modulus as a function of temperature for cortical and cancellous bones parts from cow ribs and cortical femur samples.

For temperatures higher than the shown in Figures 3, in the cancellous bone there appears the P4 to P6 peaks, see Figures 2. In contrast, for cortical parts both from ribs and femur only P4 and P5 peaks are recorded. However, it is interesting to note that, the intensities of the P4 and P5 peaks between the cortical 
and cancellous part of ribs bones are very similar. In addition, the modulus for P4 relaxation for all tested samples exhibits a step down behaviour; while for P5 and P6, it describes an increase followed by a decrease.

Therefore, the second group of differences appears among the dynamic response from bones. It is related to both the anatomical location of the bone and the type of bone. In fact, regarding to the anatomical location of the bone, the ribs bone exhibit higher P4 and P5 peaks than the femur bone. In addition, the cortical bones exhibits the appearance of P4 and P5 at higher temperatures (around $10-20 \mathrm{~K}$ ) than cancellous bone. Regarding with the bone type, i.e. cancellous or cortical, for temperatures above $600 \mathrm{~K}$ the main difference appears related to the development of P6 peak in the cancellous part of ribs bone.

In a previous work, $\mathrm{P} 4$ peak at around $510 \mathrm{~K}$ was related to the conformational changes of the collagen molecules from a triple helix structure to a random coil. Besides, the peaks in the temperature range where P5 and P6 peaks develop; were related to a subsequent stage of massive bulk deterioration of the collagen which leads to the loss of the mechanical integrity of the bulk collagen [10].

SEM studies corroborate the development of a larger degree of shrinkage of he mesostructure in the cortical part of femoral bones than in the cortical part from ribs. Figure 4 shows the evolution of the mesostructure for cortical femur bone after heating to $420 \mathrm{~K}$ and $673 \mathrm{~K}$. The loss of water after an annealing to $420 \mathrm{~K}$ leads to the compactness of the mesostructure, as it can be seen from Figure 4.b. Moreover, the increase in the annealing temperature leads to the promotion of large and deep cracks (Figure 4.c), which were absent in the fresh sample (see Figure 4.a). In contrast, for the cortical part of ribs bone, the compactness of the mesostructure after heating to $420 \mathrm{~K}$ is smaller than for femur bones, as it is shown in Figure 5.b. In addition, an increase in temperature during an annealing to $643 \mathrm{~K}$ leads to a clear compactness of the mesostructure of cortical ribs bone and also to the appearance of cracks, Figure 5.c.

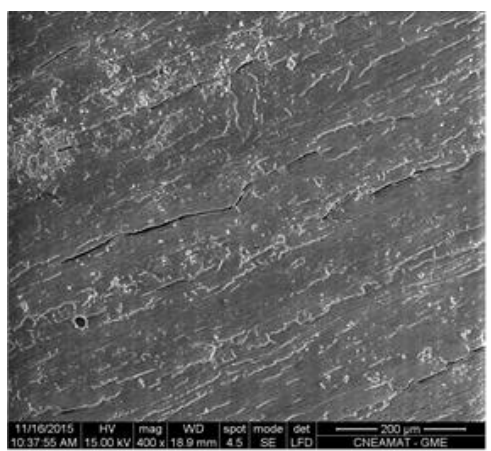

(a)

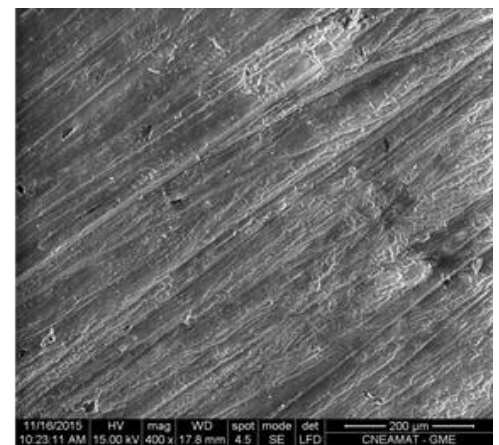

(b)

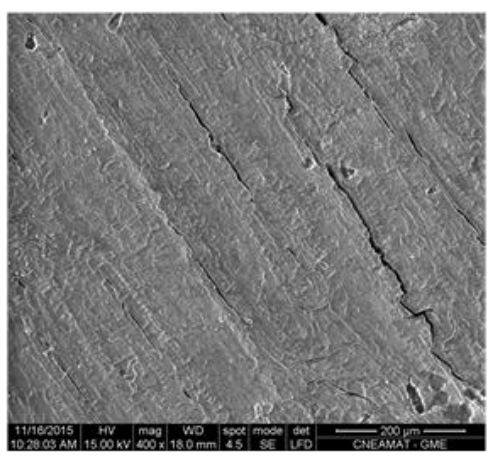

(c)

Figure 4: SEM micrographs for the cortical part of femur bone. (a) fresh state (before heating), (b) after heating to 420 $\mathrm{K}$, (c) after heating to $673 \mathrm{~K}$.

Therefore, the appearance of P2 peak in the damping spectra for cortical femur bones and its associated increase in the modulus can be related, certainly, to the shrinkage of the mesostructure promoted by the loss of water. Indeed, the shrinkage of the mesostructure after an annealing to $420 \mathrm{~K}$ is larger in the cortical part of femur bones than in the cortical part of ribs bones. The different degree of compactness of the mesostructure as a function of temperature could be related to the different arrangement of vascularisation and conformational structure of bone upon the anatomical location $[9,14]$.

Figure 6 shows the behaviour of mesostructure of the cancellous part of ribs bone during heating. The 
compactness of the mesostructure upon heating is the largest one regarding the cortical type of bone, in agreement with previous works [10-12]. The largest degree of compactness of the mesostructure in cancellous bones is in good agreement with both the highest values of damping peaks P1 and P2 and the largest increase in the modulus up to around $390 \mathrm{~K}$, in cancellous samples, see Figures 3.

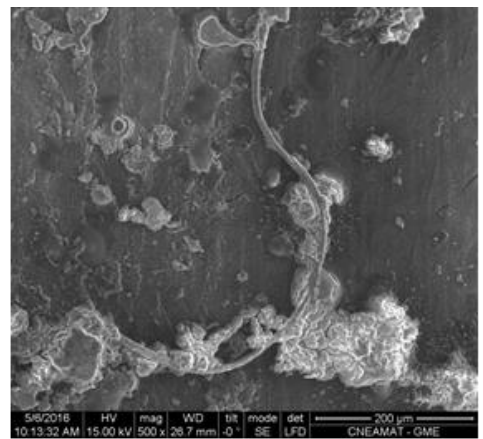

(a)

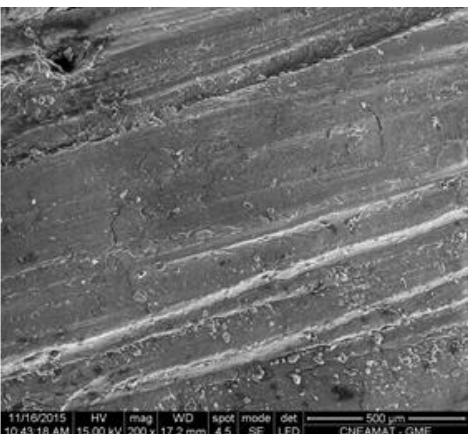

(b)

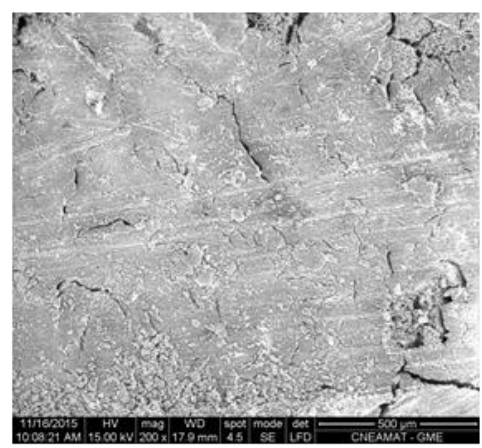

Figure 5: SEM micrographs for the cortical part of ribs bone. (a) fresh state (before heating), (b) after heating to $420 \mathrm{~K}$, (c) after heating to $673 \mathrm{~K}$.

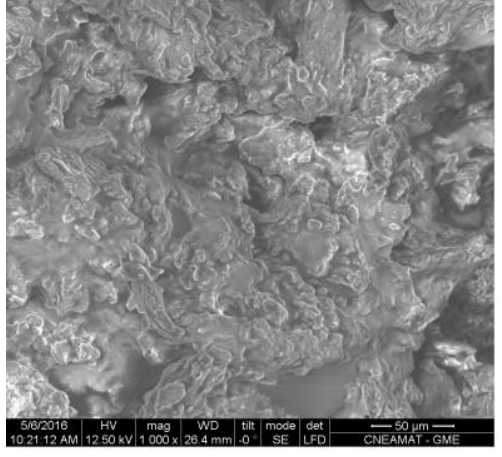

(a)

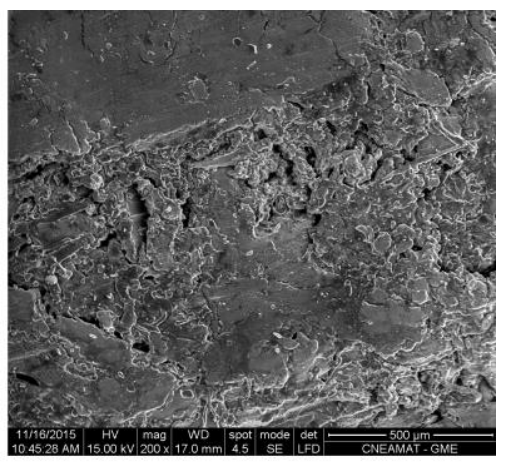

(b)

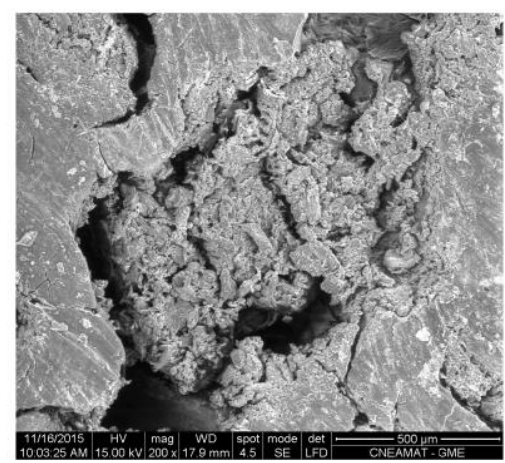

(c) 
Figure 6: SEM micrographs for the cancellous part of ribs bone. (a) fresh state (before heating), (b) after heating to 420 $\mathrm{K}$, (c) after heating to $673 \mathrm{~K}$.

In order to explain the differences which appear in the damping response related to P4 to P6 peaks, FTIR studies were carried out. Figure 7 shows the normalized infrared absorbance for cortical and cancellous ribs bone samples both in the fresh state and after heating up to $420 \mathrm{~K}$ and $673 \mathrm{~K}$. Only the wavenumber zone corresponding to the appearance of the peaks related to the Amide I, II and III between 1800 and $1200 \mathrm{~cm}^{-1}$ are shown for the sake of clarity [10,20]. Spectra were normalized in regard to the peak of the apatite at 1013 $\mathrm{cm}^{-1}$. Indeed, the most intense peak at $1013 \mathrm{~cm}^{-1}$ corresponds to the stretching vibrations of $\mathrm{PO}_{4}^{-3}$ in the apatite, which shows a high stability below $1073 \mathrm{~K}$. This is supported by the unaltered presence of $\mathrm{CO}_{3}^{-2}$ groups at $871 \mathrm{~cm}^{-1}$. However, annealing above $1073 \mathrm{~K}$ can remove this carbonate group, revealing a decomposition of the apatite $[10,21]$.

Fresh and the annealed samples were taken from the same bone. Consequently, in order to compare the behaviour of thermal denaturation of collagen due to warming over room temperature, normalizing the peak at $1013 \mathrm{~cm}^{-1}$ seems to be the more appropriate procedure. Moreover, for samples taken from different ribs, the same trend and behaviour of the FTIR spectra related to the thermal denaturation were recorded [10].

After heating up to $420 \mathrm{~K}$ the cortical part of ribs bone, the FTIR spectrum shows a decrease in the intensity of the peaks related to the Amide I, II and III at 1633,1541 and $1238 \mathrm{~cm}^{-1}$ respectively [10,20]. In addition, by increasing the annealing temperature up to $673 \mathrm{~K}$ a further decrease of these absorbance peaks is recorded. Besides, the shape of the peaks after annealing up to the different temperatures is a bit different among the samples.

In contrast, the cancellous part of ribs bones exhibits both more intense peaks related to the Amide I, II and III, and also new absorbance peaks at 1744, 1712, 1575 and $1461 \mathrm{~cm}^{-1}$ indicating, a larger amount of organic compounds than in the cortical part, as it could be expected. The increase in temperature at $420 \mathrm{~K}$ leads to a decrease in the intensity of the peaks. In addition, the annealing to $673 \mathrm{~K}$ leads to a spectrum almost overlapped to the corresponding to the cortical, but with still some remainder absorbance at 1712 and $1744 \mathrm{~cm}^{-1}$. This spectrum is not shown for clarity.

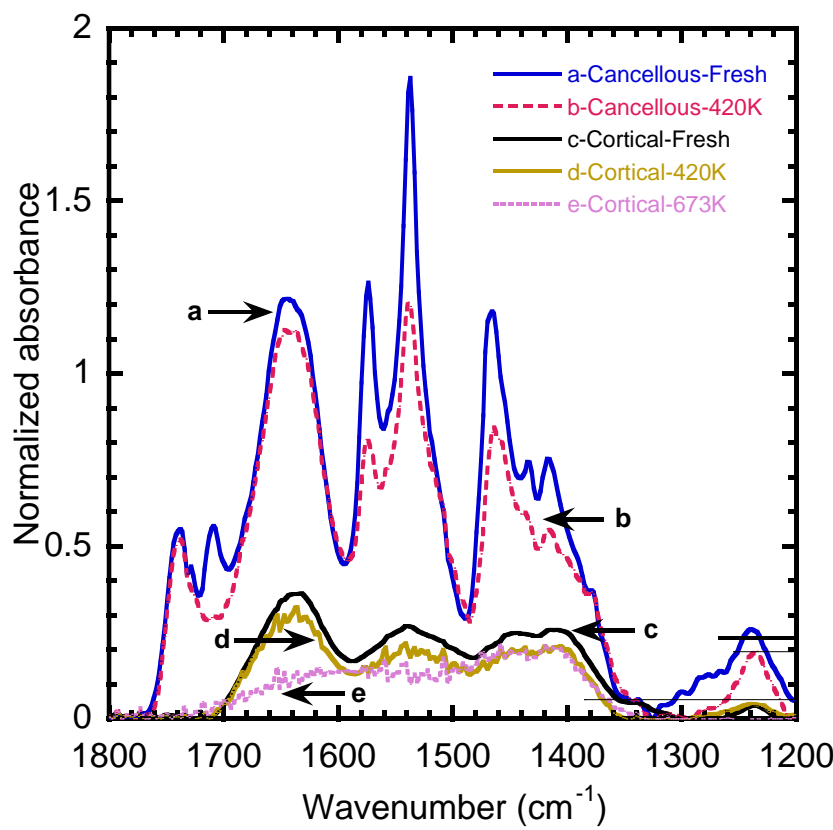

Figure 7: FTIR spectra for cortical and cancellous bones parts from cow ribs samples prior (full line) and after heating up to $420 \mathrm{~K}$ and $673 \mathrm{~K}$ (dashed line). Horizontal lines, see explanation in the text.

Figure 8 shows the FTIR spectra peaks for cortical femur bone samples in fresh state and after annealing treatments to $420 \mathrm{~K}$ and $673 \mathrm{~K}$ in the same wavenumber interval than in Figure 7. Similarly, to the cortical part of ribs bone, the annealing leads to a decrease in the intensity of the peaks related to the Amide 
I, II and III at 1633,1541 and $1238 \mathrm{~cm}^{-1}$. Spectra were also normalized in regard to the peak of the apatite at $1013 \mathrm{~cm}^{-1}$, as it was done in Figure 7.

As it can be seen by comparing Figures 7 and 8, the intensity of the absorbance peaks in fresh cortical femur bone and after annealing to $420 \mathrm{~K}$ are similar to the intensities peak measured for cortical bone from ribs. However, after an annealing up to $673 \mathrm{~K}$, the decrease in the peaks height is larger in femur samples than in both cortical and cancellous ribs bones. Horizontal lines in Figure 7 correspond to the mean maximum intensities from peaks in Figure 8. The wider line corresponds to the intensity for fresh femur sample and the shorter and longest lines correspond to the largest decrease in intensity in the spectra after a heating up to $420 \mathrm{~K}$ and $673 \mathrm{~K}$; respectively.

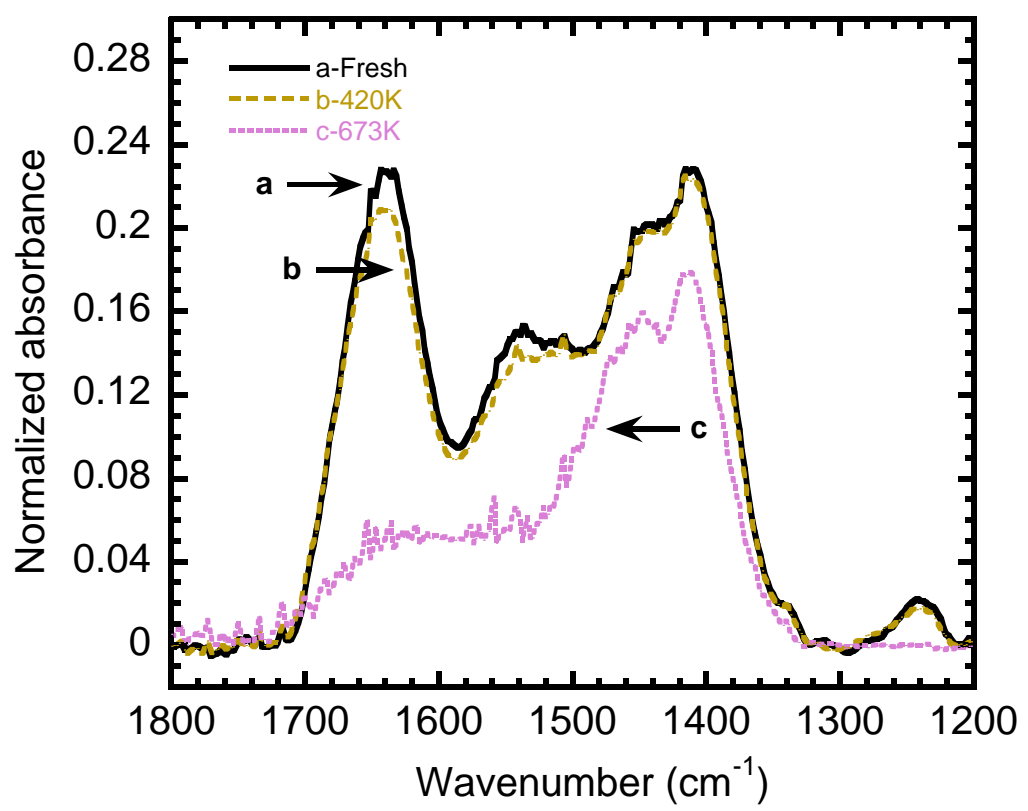

Figure 8: FTIR spectra for cortical bone from cow femur samples prior to (full line) and after a heating up to $420 \mathrm{~K}$ and $673 \mathrm{~K}$ (dashed line).

Therefore, it is clear that the amount of organic compounds regarding the apatite content in the cortical bone is similar either in femur and ribs bones, but it is smaller than in the cancellous part of ribs bone. In addition, the degree of denaturation of the collagen is larger for cancellous bone than for the cortical bones, either from femur or ribs. Nevertheless, after a warming of the sample to $673 \mathrm{~K}$, the loss of organic compounds is larger in cortical femur samples, which is revealed by the smallest intensities in the absorbance peaks. This smallest amount of organic compounds after warming up to $673 \mathrm{~K}$ in the femur bone is in agreement with the smaller damping peaks height for P4 and P5 in femur bone than both in the cancellous and cortical part of ribs bones.

Besides, the appearance of remainder absorbance peaks at 1712 and $1744 \mathrm{~cm}^{-1}$ in the cancellous sample after an annealing to $673 \mathrm{~K}$ could be the responsible of the appearance of P6 damping peak at around $650 \mathrm{~K}$ in cancellous ribs bones, see Figure 2.a. This damping peak could be related to the final denaturation of the organic compound and collagen from cancellous part of ribs bone during heating. In fact, the collagen and organic compounds are already denaturated in the cortical bones, both femoral and ribs, and then; P6 damping peak is absent in those damping spectra (see Figure 2.a).

\section{CONCLUSIONS}

The different evolution of the denaturation processes of collagen depending upon the type and anatomical location of cow bones has been determined. Six denaturation processes were identified to appear at around $320 \mathrm{~K}, 350 \mathrm{~K}, 390-410 \mathrm{~K}, 510 \mathrm{~K}, 570 \mathrm{~K}$ and $650 \mathrm{~K}$.

Denaturation process at $320 \mathrm{~K}$ developed both in femur and rib bones. It was related to the overlap of the following processes: (i) the denaturation of albumin and haemoglobin proteins and also the melting of fats, (ii) the loss of water during heating at temperatures over room temperature. 
The denaturation process at $350 \mathrm{~K}$ occurred in cancellous ribs bone and cortical femur bone, but it was absent in cortical ribs bone. The physical-chemical phenomenon controlling this denaturation process is the shrinkage of the mesostructure of bone owing to the loss of water. Indeed, the shrinkage of the mesostructure was larger in cortical femur bone than in cortical rib bone.

The collagen/protein denaturation and the loss of crystallisation water processes which develops at around $390 \mathrm{~K}-410 \mathrm{~K}$ developed only in cortical bone, either from ribs or femurs.

The denaturation process at around $510 \mathrm{~K}$, which is related to the conformational changes of the collagen molecules from a triple helix structure to a random coil, was revealed by all tested samples. In addition, denaturation processes around $560 \mathrm{~K}$, which are related to a subsequent stage of massive bulk deterioration of the collagen leading to the loss of the mechanical integrity of the bulk collagen, was also revealed by all tested samples. However, the intensity of these damping peaks is higher in ribs bone than in femurs bone. This phenomenon is controlled by a larger denaturation degree of organic compounds after heating to $573 \mathrm{~K}$ in ribs bones than in femurs bones. Moreover, the denaturation process at around $650 \mathrm{~K}$ was only present in cancellous ribs bone due to the reminder of some organic compounds after heating up to 673 K.

The results from the present work highlight that it is not possible to extrapolate the thermal denaturation processes among collagen from bones at different anatomical locations. This point is crucial in order to relate the thermal denaturation processes both to crystallinity and maturation of collagen, as well as connective tissue diseases, for bone replacement or tissue engineering in medicine. In addition, it represents a great tool helping to the study of identification of buried and/or burned bones in archaeological sites.

\section{ACKNOWLEDGMENTS}

This work was partially supported by the CONICET PIP No. 179CO and the PID-UNR ING 453 (20142017).

\section{BIBLIOGRAPHY}

[1] LAU, M., LAU, K., KU, H., CARDONA, F., et al., "Analysis of heat-treated bovine cortical bone by thermal gravimetric and nanoindentation”, Composites Part B: Engineering, v. 55, pp. 447-452, Dec. 2013.

[2] VIGUET-CARRIN, S., GARNERO, P., DELMAS, P. D., "The role of collagen in bone strength", Osteoporosis International, v. 17, n. 3, pp. 319-336, Mar. 2006.

[3] MLYNIEC, A., TOMASZEWSKI, K.A., SPIESZ, E.M., et al., "Molecular-based nonlinear viscoelastic chemomechanical model incorporating thermal denaturation kinetics of collagen fibrous biomaterials", Polymer Degradation and Stability, v. 119, pp. 87-95, Sep. 2015.

[4] UZEL, S.G.M., BUEHLER, M.J., "Molecular structure, mechanical behavior and failure mechanism of the C-terminal cross-link domain in type I collagen", Journal of the Mechanical Behavior of Biomedical Materials, v.4, n. 2, pp. 153-161, Feb. 2011.

[5] NOWOTNY, K., GRUNE, T., "Degradation of oxidized and glycoxidized collagen: role of collagen cross-linking", Archives of Biochemistry and Biophysics, v. 542, pp. 56-64, Jan. 2014.

[6] CREMER, M.A., ROSLONIEC, E.F., KANG. A.H., "The cartilage collagens: a review of their structure, organization, and role in the pathogenesis of experimental arthritis in animals and in human rheumatic disease", Journal of Molecular Medicine, v. 76, n. 3, pp. 275-288, Feb. 1998.

[7] VERZIJL, N., DEGROOT, J., ZAKEN, C. B., BRAUN-BENJAMIN, O., et al., "Crosslinking by advanced glycation end products increases the stiffness of the collagen network in human articular cartilage: a possible mechanism through", Arthritis \& Rheumatology, v. 46, n. 1, pp. 114-123, Jan. 2002.

[8] BOZEC, L., ODLYHA, M., "Thermal denaturation studies of collagen by microthermal analysis and atomic force microscopy", Biophysical Journal, v. 101, n. 1, pp. 228-36, Jul. 2011.

[9] MANO, J. F., "Viscoelastic properties of bone: Mechanical spectroscopy studies on a chicken model", Materials Science and Engineering: C, v. 25, n. 2, pp. 145-152, Apr. 2005.

[10] LAMBRI, M. L., GIORDANO, E. D., BOZZANO, P. B., et al., “Thermal Degradation of Type I Collagen from Bones", Journal of Renewable Materials, v. 4, n. 4, pp. 251-257, 2016.

[11] LAMBRI, M. L., PÉREZ-LANDAZÁBAL., J. I., RECARTE, V., et al., "Effect of the mesostructure on the mechanical dynamical behaviour in cancellous bones", Acta Microscópica, v. 22, n. 1, pp. 26-31, 2013.

[12] LAMBRI, O. A., PÉREZ-LANDAZÁBAL, J. I., BONIFACICH, F. G., et al., "Damping 
Micromechanisms for Bones above Room Temperature", Journal of Biomaterials and Tissue Engineering, v. 19, pp. 87-98, 2014.

[13] PIETRUCHA, K., "Changes in denaturation and rheological properties of collagen-hyaluronic acid scaffolds as a result of temperature dependencies", International Journal of Biological Macromolecules, v. 36, n.5, pp. 299-304, 2005.

[14] GARNER, E., LAKES, R., LEE, T., et al., "Viscoelastic dissipation in compact bone: implications for stress-induced fluid flow in bone”, Journal of biomechanical engineering, v. 122, n. 2, pp. 166-172, 2000.

[15] TOMASSETTI, M., MARINI, F., CAMPANELLA, L., et al., "Study of modern or ancient collagen and human fossil bones from an archaeological site of middle Nile by thermal analysis and chemometrics", Microchemical Journal, v. 108, pp. 7-13, 2013.

[16] PIGA, G., SANTOS-CUBEDO, A., BRUNETTI, A., et al., “A multi-technique approach by XRD, XRF, FT-IR to characterize the diagenesis of dinosaur bones from Spain”, Palaeogeography, Palaeoclimatology, Palaeoecology, v. 310, n.1, pp. 92-107, 2011.

[17] STINER, M.C., KUHN, S.L., WEINER, S., et al., "Differential burning, recrystallization, and fragmentation of archaeological bone”, Journal of Archaeological Science, v. 22, n. 2, pp. 223-237, 1995.

[18] SCHALLER, R., FANTOZZI, G., GREMAUD. G. (eds.), Mechanical Spectroscopy. Switzerland, Trans. Tech. Publ. Ltd, 2001.

[19] LAMBRI, O.A. "A review on the problem of measuring nonlinear damping and the obtainment of intrinsic damping”, In: Martinez-Mardones, J., Walgraef, D., Wörner, C.H. (eds.)., Materials Instabilities, New York, USA, World Scientific Publishing Co Pte Ltd, 2000.

[20] FIGUEIREDO, M., GAMELAS, J., MARTINS, A., "Characterization of bone and bone-based graft materials using FTIR spectroscopy”, In: THEOPHANIDES, T. (ed.), Infrared Spectroscopy - Life and Biomedical Sciences, InTech, 2012.

[21] OOI, C. Y., HAMDI, M., RAMESH, S., "Properties of hydroxyapatite produced by annealing of bovine bone”, Ceramics International, v. 33, n. 7, pp. 1171-1177, 2007. 